\title{
Randomised controlled trial assessing the effectiveness of a booklet on the duration of breast feeding
}

Vincenzo Currò, Roberta Lanni, Fanny Scipione, Valentina Grimaldi, Pierpaolo Mastroiacovo

\begin{abstract}
Objective-To test the efficacy of an information booklet to increase the duration of breast feeding.

Research design-Randomised design, stratifying by maternal residence and working activity. Two hundred women were recruited, 103 received the booklet and verbal counselling and 97 verbal counselling only.

Population-Infants observed from 15 September 1993 to 15 June 1994 in the well baby outpatient clinic of the Paediatric Institute of the Catholic University of Rome, Italy.

Main results-No statistically significant difference was found between the two groups in the prevalence of exclusive or complementary breast feeding at 6 months of age: $48.5 \%$ and $59.2 \%$ in the intervention group, $43.7 \%$ and $51.5 \%$ in the control group. The median duration of exclusive or complementary breast feeding was 24 and 27 weeks in the treated group, 22 and 25 in the control group.

Conclusions-The information booklet alone does not seem to increase the duration and the prevalence of breast feeding at 6 months of age. The use of written material with a more individualised support and more extensive use of randomised clinical trials in the evaluation of health promoting programmes is recommended.

(Arch Dis Child 1997;76:500-504)
\end{abstract}

Keywords: breast feeding; health information evaluation; randomised controlled trial

Exclusive breast feeding up to 6 months is currently recommended in developed as well as in developing countries as the optimal feeding mode for all infants. ${ }^{1}$ The advantages of breast feeding observed in developed countries include: reduction of mortality rate and prevention of some bacterial illnesses such as otitis media, lower respiratory tract infection, bacteraemia and meningitis; reduction of certain immunological disorders as well as of certain chronic diseases; promotion of mother-infant interaction and bonding; and a substantial economic impact. ${ }^{2-4}$

Despite the above mentioned recommendation and advantages, in Italy recent studies found that although $62 \%-84 \%$ of women started exclusive breast feeding, only $19 \%-23 \%$ continued to 6 months. $^{5-7}$ These findings suggest that at least in some countries the major challenge is duration rather than initiation. The reasons given by mothers for early cessation of breast feeding and factors associated with short duration have been widely investigated. ${ }^{8-11}$ After considering the results of these investigations various kind of education programmes have been designed. ${ }^{12}$ Some have used pamphlets or booklets to reinforce individualised counselling, to increase the credibility of the advice given, and to counteract popular belief. With this rationale many pamphlets on breast feeding have been produced and distributed to new mothers in Italy, where other resources (for example the 'BabyFriendly Hospital Initiative', health home visitors, telephone lines) are not available. Although the readability and the compliance of pamphlets or booklets for promoting breast feeding with the World Health Organisation (WHO)/Unicef code on marketing of breast milk substitutes have been evaluated, ${ }^{13}$ the evidence of their efficacy when used with individualised counselling is lacking. As in Italy the paediatrician is alone in promoting breast feeding our hypothesis was that a simple intervention, such as as a booklet given after the usual advice, could be effective in increasing the duration of breast feeding.

We report the results of a randomised controlled trial that evaluated the efficacy of an information booklet for prolonging the duration of breast feeding up to 6 months of age in a well baby outpatient clinic.

\section{Subjects and methods}

STUDY POPULATION

The study was conducted from 15 September 1993 to 15 June 1994 in the well baby outpatient clinic of the Paediatric Institute of the Catholic University of Rome. The well baby outpatient clinic serves a heterogeneous population that lives in the city of Rome and in neighbouring towns. The clinic usually provides the first control visit after birth during the first two to three weeks of life. Follow up visits are provided by the local paediatric services or by the clinic.

\section{RECRUITMENT}

To be eligible, a woman had to: (a) be a primipara; (b) have delivered an infant with a birth weight of $2500 \mathrm{~g}$ and without any major prob- 
lem; (c) be currently exclusively breast feeding; and (d) be fluent in Italian. Eligible mothers were recruited among those who delivered in 11 hospitals and clinics (private and public) in Rome during the study period. Eligible women were contacted at the first postnatal visit (10-20 days after birth).

The trial was explained to all eligible women and consent was obtained before the visit. Ninety seven per cent of all the eligible women who were asked to take part agreed to participate in the study.

\section{INTERVENTION}

A 10 minute counselling session on breast feeding was provided to all women during the paediatric visit. 'Treated' women also received a booklet containing a set of instructions for practical breast feeding management. This booklet was similar to that approved by the American Academy of Pediatrics ${ }^{14}$ and included information (both as text and figures) about the advantages of exclusive breast feeding particularly if prolonged for the first six months of life, feeding positions, mother's diet, common concerns and beliefs, feeding schedules, care of nipples, and other relevant topics. The booklet is available on request.

\section{STUDY DESIGN}

A stratified randomised design was used.

Stratification was done by maternal residence (in Rome city, out of Rome city, out of Rome county) and by maternal occupation before pregnancy (housewife, working in the public sector, working in a private setting) as these two variables were seen as a better predictor of breast feeding duration than maternal education or paternal working activity. ${ }^{7}$ After the allocation to one of the two groups (treated = oral counselling and booklet; controls $=$ oral counselling only), one of us (VC) gave the booklet explaining its importance as a reference manual for further help.

MEASUREMENT OF VARIABLES

At the time of recruitment and before randomisation, the paediatrician in charge conducted a structured interview with each woman to ascertain a set of demographic (residence, maternal working activity), maternal (that is smoking habit, delivery mode, maternal diseases), and neonatal (that is birth weight, gestational age, Apgar score, rooming-in) characteristics.

The infant's feeding history up to 6 months was assessed approximately at seven months' postpartum by a structured telephone interview performed by one of us (FS) unaware of the treatment status of the study mothers up to the final questions about the booklet. Mothers were considered to have exclusively breast fed if they had given the infant only breast milk during the period, except water or water based drinks and medicines (WHO Division of Diarrhoeal and Acute Respiratory Disease Control, informal meeting 11-12 June 1991). Duration of exclusive breast feeding was calculated as number of weeks from the infant's birth until formula or a solid food was introduced. Complementary breast feeding was defined as having given any breast milk and any food or liquid including non-human milk (WHO Division of Diarrhoeal and Acute Respiratory Disease Control, informal meeting 11-12 June 1991). We also assessed knowledge of the existence of the booklet, its use during the breast feeding period, and how useful mothers found it.

\section{DATA ANALYSIS}

To test the hypothesis of an increased rate of breast feeding at 6 months, from $50 \%$ to $70 \%$, with a two tail alpha level of 0.05 and a 1-beta level of 0.80 , at least 95 pairs were needed. The probability of being still exclusive or complementary breast fed at each week of life in treated and control group was estimated by Kaplan-Meyer method using EGRET software..$^{15}$ The analysis was performed up to 6 months of age. Log rank test was used for statistical comparisons.

\section{Results}

Two hundred women were recruited, 103 were allocated to the treatment group and 97 to the control group; no women were lost to follow up. The results of randomisation are shown in table 1. Maternal parity in the treated and control groups was identical by design eligibility criteria. Working activity and residence were similar as they were stratification variables. No statistically significant differences were seen in the other variables in the two groups. None of the mothers received commercial discharge packs in the delivery hospital. None had roomed-in. The median duration of exclusive breast feeding for those receiving the booklet was 24 weeks (interquartile range 13-31) compared with 22 weeks for those not receiving the booklet (interquartile range 13-29). The median duration of complementary breast feeding for those receiving the booklet was 27 weeks (interquartile range 17-35) compared with 25 weeks (interquartile range 17-30) for those not receiving the booklet. Figure 1 shows the prevalence rate of exclusive and complementary breast feeding in the treated and control group. At 26 weeks ( 6 months) the prevalence of exclusive breast feeding was $48.5 \%$ among treated infants compared with $43.7 \%$ among non-treated infants with a rate difference between groups of $4.7 \% \quad(95 \%$ confidence interval (CI) -9.2 to 18.7 ). The prevalence of complementary breast feeding was respectively $59.2 \%$ and $51.5 \%$, with a rate difference between groups of $7.7 \%$ (95\% CI 95\% -6.1 to 21.4). The log rank test showed no statistically significant differences between treated and non-treated mothers regarding the duration of exclusive $(p=0.52)$ or complementary breast feeding $(\mathrm{p}=0.35)$.

\section{Discussion}

This trial was to assess in unbiased fashion whether or not giving an information booklet increases the duration of breast feeding up to 6 months among mothers who start exclusive breast feeding. These women usually breast fed 
Table 1 Comparability of groups of women given the booklet and controls; values are per cent

\begin{tabular}{lll}
\hline & Treated $(n=103)$ & Controls $(n=97)$ \\
\hline Maternal age at delivery (years) & & \\
$<20$ & 1.0 & 0 \\
$20-24$ & 14.5 & 11.4 \\
$25-29$ & 40.8 & 43.3 \\
$30-34$ & 36.9 & 31.9 \\
$35-39$ & 4.9 & 12.4 \\
$\geqslant 40$ & 1.9 & 1.0 \\
Infant's sex & 41.7 & 50.6 \\
Male & 58.3 & 49.4 \\
Female & & \\
Birth weight (g) & $3300(3100-3510)$ & $3270(3080-3540)$ \\
Median (interquartile range) & 12.6 & 15.5 \\
$2500-2999$ & 60.2 & 55.7 \\
3000-3499 & 27.2 & 28.8 \\
$\geqslant 3500$ & $40(39-42)$ & $40(39-42)$ \\
Gestational age (weeks) & 3.9 & 4.1 \\
Median (interquartile range) & 96.1 & 95.9 \\
$\quad<37$ & 75.7 & 81.4 \\
$\geqslant 37$ & 24.3 & 18.6 \\
Type of delivery & & \\
Vaginal & 15.6 & 21.6 \\
Caesarean section & 4.8 & 11.3 \\
Smoking & & 27.8 \\
During pregnancy & 25.2 & 72.2 \\
During breast feeding & 74.8 & \\
Follow up & & \\
Performed by well baby outpatient clinic & & \\
Performed outside & & \\
\hline
\end{tabular}

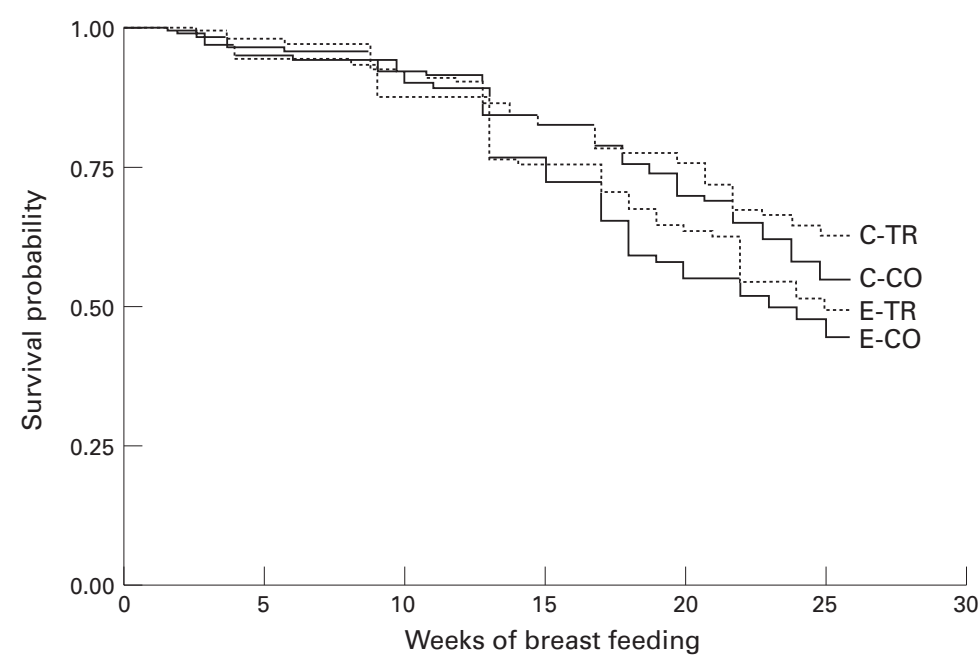

Figure 1 Prevalence of complementary (C) and exclusive (E) breast feeding by weeks in treated (TR) and control (CO) groups.

their infants for at least the first 15-20 days of life. The aim of our study was not to promote or assess the initiation of breast feeding. The information booklet did not increase the prevalence of breast feeding at 6 months when given to primiparous mothers who breast fed from birth. This negative result cannot be explained by ignorance of the messages. Mothers were asked if they had read and used the booklet. All of them without exception used the booklet, at least once. Inappropriateness of messages is improbable as the booklet was modelled taking into account the booklet approved by the American Academy of Pediatrics and the $\mathrm{WHO} /$ Unicef code on marketing of breast milk substitutes. ${ }^{14}$ Moreover, $82 \%$ of 'treated' mothers reported having found it useful. The possibility of a cointervention is unlikely as the booklet was given on an individual basis and all untreated mothers, although knowing the existence of a booklet under evaluation, were not able to recall the front page drawing of the booklet we actually used. The possibility that control mothers used other similar booklets or some kind of written information does not explain the results as $57 \%$ of them reported that they would have been pleased to have available a specific booklet at some point during their breast feeding experience. The variation in the care routines and the prepartum attitudes towards breast feeding could be partially controlled by the stratified randomisation.

Characteristics of the study site and sample as well as features of the study design should be considered in interpreting these results. The well baby outpatient clinic in which the study was conducted was strongly committed to the promotion of breast feeding. Second, the study participants represent a selected sample of women. All women in the study were primiparae, and breast fed their babies at hospital discharge. None received a commercial formula package, and none of the infants had a low birth weight. Therefore two known risk factors for shortening breast feeding were not present. ${ }^{17}{ }^{18}$ All these features may explain the high rate of breast feeding at 6 months obtained in the control group and may explain the very small, statistically non-significant, rate difference in prolonging breast feeding obtained in this study.

There are two possible explanations of our results. The first is that traditional verbal counselling and advice used by us at the beginning, as well as that used in routine care by the local services, provokes a plateau of duration which cannot be increased easily with a booklet. The second is that a booklet alone is not sufficient. It is well known that breast feeding practice is influenced not only by knowledge, but also by many social and psychological factors as well as by some practical help and by close contact with well trained health professionals. It is unclear whether or not the same kind of intervention could be useful in a different setting or for those mothers at higher risk for early interruption of breast feeding.

Randomised controlled trials provide the most compelling evidence of efficacy. We have found no other randomised controlled trial of the efficacy of a booklet to promote the initiation or duration of breast feeding, and only a few trials of health education booklets or leaflets in other health promotion settings. ${ }^{19} 20$ Although written material is perceived as low cost and unlikely to cause harm, there are substantial costs with promoting strategies of unproved effect. The results of this study suggests that the efficacy of written information alone in prolonging breast feeding is very limited among those infants who are already breast fed at discharge. However, written information is well accepted and desired by parents. We feel that a booklet may be of value if a more promotional approach can be designed, for example in conjunction with other more individualised tools such as a telephone line or health worker support. 
We thank the Fondazione ASM per la Salute dell'Infanzia for supporting the study and Rani Bhullar, Gabriella Giordani, and Agnese Era for technical assistance.

$1 \mathrm{WHO} /$ Unicef Joint Statement. Protecting, promoting and supporting breast-feeding: the special role of maternity services. Geneva: WHO, 1989

2 Cunningham AS, Jelliffe DB, Jelliffe EFP. Breast-feeding and health in the 1980s: a global epidemiologic review. $\mathscr{F}$ Pediatr 1991;118:659-66.

3 Freed GL. Breast-feeding. Time to teach what we preach. $7 A M A$ 1993;269:243-5.

4 Goldfarb J, Tibbetts E, eds. Breastfeeding — advantages and Goldfarb J, Tibbetts E, eds. Breastfeeding-advantages and issues. Breastfeeding handbook. A practical reference for physicians, nurses, and other health prof

5 Conti Nibali S, Castorina N, Pizzimenti G, Salomone L, Siracusano MF. La pratica dell'allattamento al seno. Medico e Bambino 1995;9:457-63.

6 Sardini S, Simeoni G, Russo E, Cermaria F, Zanini F. Indagine epidemiologica sulla pratica dell'allattamento al seno nella popolazione consultoriale dell'USSL 46 'Alto Mantovano'-Regione Lombardia. Minerva Pediatr 1993 45:181-7.

7 Gruppo di studio 'Progetto Mercurio'. Nota redatta da: Lanni R, Grimaldi V, Corchia C, Cascioli C, Baldassarre S Mastroiacovo P. L'allattamento materno in Italia: studio di coorte proveniente da un'indagine multicentrica italiana. Ital F Pediatr 1995;21/S3:189.

8 Birenbaum E, Vila Y, Linder N, Reichman B. Continuation of breast-feeding in an Israeli population. $\mathcal{F}$ Pediatr Gastroof breast-feeding in an Israe
enterol Nutr 1993;16:311-5.

9 Michaelsen KF, Larsen PS, Thomsen BL, Samuelson G The Copenhagen cohort study on infant nutrition and The Copenhagen cohort study on infant nutrition and
growth: duration of breast feeding and influencing factors. Arowth: duration of breast feeding

10 Jakobsen MS, Sodemann M, Molbak K, Aaby P. Reason for termination of breastfeeding and the length of breastfeed ing. Int $\mathcal{F}$ Epidemiol 1996;25:115-21

11 Weile B, Rubin DH, Krasilnikoff PA, Kuo HS, Jekel JF Infant feeding patterns during the first year of life in Denmark: factors associated with the discontinuation of breast-feeding. F Clin Epidemiol 1990;43:1305-11.

12 Bocar DL, Shrago L. Breastfeeding education. In: Riordan $\mathrm{J}$, Auerbach KG, eds. Breastfeeding and human lactation. Boston: Jones and Bartlett, 1993.

13 Valaitis RK, Shea E. An evaluation of breastfeeding promotion literature: does it really promote breastfeeding? Can $\mathcal{F}$ Public Health 1993;84:24-7.

14 Teitel M, Delaney S, Fink L. Breast feeding the art of mothering. Port Washington, NY: Alive Productionns Ltd, 1987.

15 Kaplan EL, Meier P. Non-parametric estimation from incomplete observations. Fournal of the American Statistical incomplete observations. fourn

16 Statistics and Epidemiology Research Corporation. EGRET. Seattle: Statistics and Epidemiology Research Corporation, 1991

17 Dungy CI, Christensen-Szalansky J, Losch M, Russel D. Effects of discharge samples on duration of breast-feeding. Pediatrics 1992;90:233-7.

18 Ryan AS, Rush D, Krieger FW, Lewandowsky GE. Recent decline in breast-feeding in the United States, 1984 through 1989. Pediatrics 1991;88:719-27.

19 Dey P, Collins S, Will S, Woodma CBJ. Randomised controlled trial assessing effectiveness of health education leaflets in reducing incidence of sunburn. BMF 1995;311: 1062-3.

20 McAvoy BR, Raza R. Can health education increase uptake of cervical smear testing among Asian women? BMF 1991; 302:833-6.

\section{Commentary}

IMPROVING THE DURATION OF BREAST FEEDING

It is welcome to see a randomised controlled trial, that holy grail of epidemiologists, applied to health promotion even with negative results. The authors imply that breast feeding has limited support in Italy (no mothers roomed-in in hospital, paediatricians were alone in promoting breast feeding). It is therefore hardly surprising that a booklet alone does not make a difference. The provision of a booklet is based on the premise that mothers need more information about breast feeding. This is undoubtedly true, but it would be quite a false assumption to consider that provision of information leads to behaviour change. It is now well established that cultural beliefs, peer support, economic factors, and marketing pressure are equally, if not more, important than education in influencing health behaviour. ${ }^{1}$ This is not to negate the value of information, which has been demonstrated to be effective in child injury prevention. ${ }^{2}$ But it should certainly not be used alone. Also the provision of a booklet is not the same as provision of information, as its use depends on the mother's literacy skills, the availability of the booklet at the time it is needed, and the interpretation of its contents.

Improving the duration of breast feeding is a highly desirable objective. It is remarkable that both groups of mothers breast fed for so long: $48.5 \%$ were exclusively breast feeding at 6 months in the treated group and $43.7 \%$ in the non-treated. This compares with $30 \%$ at 12 weeks in Newcastle upon Tyne. ${ }^{3}$ The authors state that the participants were a selected group and this may be the explanation. There is no mention of socioeconomic status, which is a key variable, and I wonder if most of the mothers were from a higher income group.

WHICH INTERVENTIONS WORK?

Interventions that are more likely to increase the duration of breast feeding are based on mothers' expressed reasons for giving up ${ }^{3}$ : employment, baby hungry or crying, sore nipples, 'insufficient milk', pressure from father or relative. Such interventions would include ${ }^{4}$ longer maternity leave, the introduction of breast feeding policies in the health sector, better facilities for breast feeding at work, a breast feeding support and advisory service (preferably using experienced breast feeding mothers), and a more pro-breast feeding social climate. None of these is as easy to institute or administer as the provision of information and this is a great problem for the community based researcher who wishes to use a randomised controlled trial. The provision of a booklet, like the delivery of immunisation, is a single intervention that is carried out in the health sector and which can readily be prescribed, like a drug. But its effectiveness is likely to be very limited. A randomised controlled trial is extremely difficult to apply to an intervention such as the La Leche League peer counselling system, ${ }^{5}$ which is community based, and recruits breast feeding mothers in low socioeconomic areas as information and support givers. A randomised controlled trial on this intervention would be difficult because the scheme is rooted in the community and affects all mothers living there, and also it is difficult and time consuming to set up, hence randomisation at an individual level would not be possible.

However, this does not mean that evaluation of the effectiveness of broader health promotion initiatives is not possible-rather that a variety of different methods will require to be used, including qualitative research.

The promotion of breast feeding is a key area of paediatrics and it is important for researchers to engage in evaluation of interventions on a wider basis than that described in this article, covering peer support and breast feeding policies for professionals as well as education.

TONY WATERSTON Newcastle City Health NHS Trust, Division of Community Health, Arthur's Hill Clinic, Douglas Terrace, Nerwcastle upon Tyne NE4 6BT 
1 Kimti V. Cultural aspects of common childhood diseases. In: Stanfield P, Brueton $\mathrm{M}$, Chan $\mathrm{M}$, Parkin $\mathrm{M}$, Waterston T,
eds. Diseases of children in the subtropics and tropics. 4th Ed. eds. Diseases of children in the subtropics
London: Edward Arnold, 1991:14-24.

2 Colver A, Hutchinson P, Judson E. Promoting children's home safety. BMF 1982;285:1177.

3 Fitzgerald A. Health outcomes: breastfeeding survey. Newcastle upon Tyne: Newcastle City Health Trust, 1995.

4 Jelliffe DB, Jelliffe EFP, eds. Programmes to promote breastfeeding. Oxford: Oxford University Press, 1988.

$5 \mathrm{La}$ Leche League of Great Britain. Breastfeeding peer counsellor programme. Nottingham: La Leche League, 1992. (Information from: La Leche League, PO Box 29, West Bridgford, Nottingham NG2 6FX.) 